\title{
Fabrication and Deployment Testing of Solar Sail Quadrants for a 20-meter Solar Sail Ground Test System Demonstration \\ Greg Laue
}

SRS Technologies, Huntsville, AL 35806, United States

David Case ${ }^{\dagger}$ and Jim Moore ${ }^{\ddagger}$

SRS Technologies, Huntsville, AL 35806, United States

\begin{abstract}
A 20-meter Scalable Square Solar Sail $\left(S^{4}\right)$ System was produced and successfully completed functional vacuum testing in NASA Glenn's Space Power Facility at Plum Brook Station Ohio in May 2005. The $\mathrm{S}^{4}$ system was designed and developed by ATK Space Systems, and the design and production of the Solar Sails for this system was carried out by SRS Technologies. The $S^{4}$ system consists of a central structure with four deployable carbon fiber masts that support four triangular sails. SRS has developed an effective and efficient design for triangular sail quadrants that are supported at three points and provide a flat reflective surface with a high fill factor. This sail design is robust enough for deployments in a one atmosphere, one gravity environment and incorporates several advanced features including adhesiveless seaming of membrane strips, compliant edge borders to allow for film membrane cord strain mismatch without causing wrinkling and low mass $(3 \%$ of total sail mass) ripstop. This paper will outline some of the sail design and fabrication processes and the mature production, packaging and deployment processes that have been developed. This paper will also detail the successful ambient and vacuum testing of the sails and the ATK spacecraft structure. Based on recent experience and testing, SRS is confidant that high Technology Readiness Level (TRL) 5-6 solar sails in the 40-120-meter size range with areal density in the $4-5 \mathrm{~g} / \mathrm{m}^{2}$ (sail minus structure) range can be produced with existing technology. Additional film production research will lead to further reductions in film thickness to less than 1 micron enabling production of sails with areal densities as low as $2.0 \mathrm{~g} / \mathrm{m}^{2}$ using the current design, resulting in a system areal densities as low as $5.3 \mathrm{~g} / \mathrm{m}^{2}$ (sail and structure). These areal densities are low enough to allow nearly all of the Solar Sail missions that have been proposed by the scientific community. The fundamental technologies required to produce these systems has been demonstrated on the 20-meter $S^{4}$ sails that have recently completed ground testing demonstrating a mature and technology suitable for incorporation into future flight validation and future mission. Solar Sails can support NASA's Vision for Space Exploration by allowing communication satellite orbits that can maintain continuous communication with the polar regions of the Moon and Mars and to support solar weather monitoring to provide early warning of solar flares and storms that could threaten the safety of astronauts and other spacecraft.
\end{abstract}

\section{Introduction}

Solar sails are one of the high priority technologies being developed by NASA's In-Space Propulsion Technology Program (ISP) ${ }^{1,2}$. In order to develop solar sail technology to the point where it is mature enough to successfully execute a system demonstration flight experiment the ISP program has awarded two competing teams contracts to design, fabricate and test 10-meter and 20-meter system ground demonstrations. One of these teams is the Scalable Square Solar Sail Team ( $\mathrm{S}^{4}$ Team) consisting of ATK Space Systems (System Design/Integration), SRS Technologies (Sail Subsystem) ASU (ACS Control Modeling) and Princeton Satellite systems (Flight Software) ${ }^{3}$.

\footnotetext{
*Engineer, Aerospace Technologies Directorate, 500 Discovery Drive, Huntsville, AL 35806, and MB.

${ }^{\dagger}$ Engineer, Aerospace Technologies Directorate, 500 Discovery Drive, Huntsville, AL 35806

‡ Engineer, Aerospace Technologies Directorate, 500 Discovery Drive, Huntsville, AL 35806, and MB.
}

1 
The Scalable Square Solar Sail $\left(S^{4}\right)$ concept was designed such that a single system architecture could be scaled to produce different size sail craft appropriate to a large number of missions. The basic architecture was created around a boom optimized for an 80 meter system of which truncated systems of 10 and 20-meters would be ground tested. From June of 2003 thru May of 2004 a 10-meter version of a single quadrant or one quadrant $\mathrm{S}^{4}$ system was designed, produced and tested. This system consisted of two booms, a simulated spacecraft hub, and a triangular sail quadrant and is shown in Fig. 1 and Fig. 2. The 10-meter single quadrant test hardware represented one fourth of a three axis stabilized square solar sail propulsion system. The sail was designed to be suspended by tensioning it between the three attachment points located at the spacecraft hub and the two boom tips. This test series validated the basic design and construction techniques and materials used to build package and deploy this type of structure.

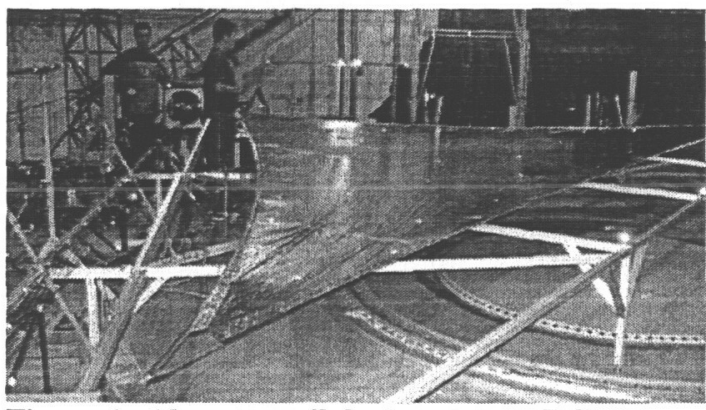

Figure 1. 10-meter sail deployed at LaRC.

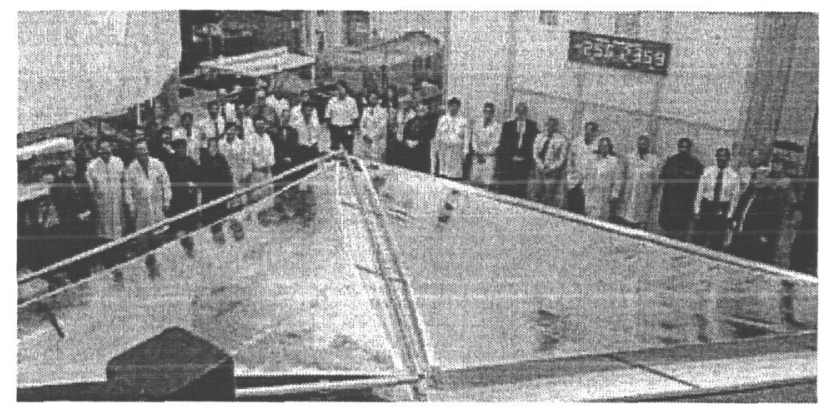

Figure 2. Two 10-meter sails at SRS during Phase I final review.

In June of 2004 efforts began to design and build a full four quadrant 20-meter sail system for ground testing. This system consists of four sail booms, an instrument boom, a system bus structure, primary ACS (Attitude Control System) and four triangular sails identified as PS20-1, PS20-2, PS20-3, and PS20-4. The ground demonstration of this system under vacuum in May of 2005 constituted as close to a full flight like system test as can be performed in a one gravity environment. A top view of the deployed system is shown in fig 3 and a schematic layout for the ground test system is shown in Fig. 4. Fig. 5 illustrates the nomenclature used to describe the 20-meter Sails and some of the key sail dimensions.

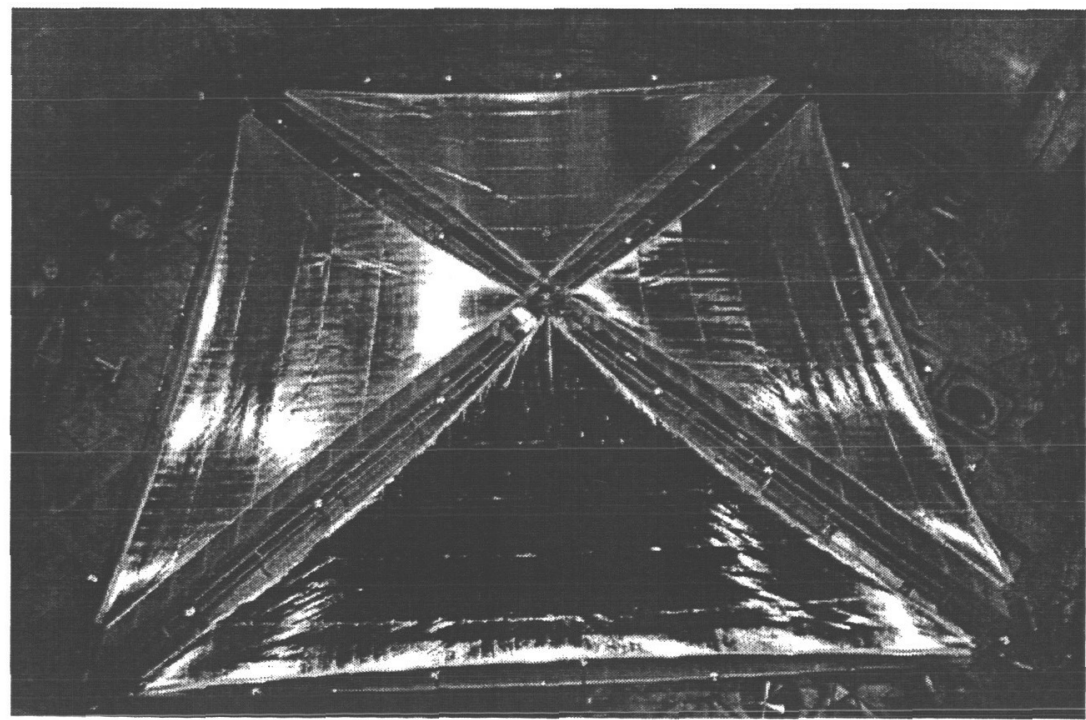

Figure 3. Deployed 20-meter ground test sail craft overhead picture. 
The basic SRS sail design consists of a cord, a compliant border, and the sail film. The main benefit of the SRS design is that the exterior cord and compliant border allow the sail to be loaded in a biaxial stress state from three points ${ }^{4,5}$. This provides a flat uniform reflective surface that produces very little scatter and distortion. The simplicity, stability, and predictability of this design allows for an easily modeled reflective surface and greatly simplifies the analysis and margin required for designing an attitude control system for a square solar sail flight system.

The ATK support system consists of a central structure that houses the storage bays for the deployment booms and the sails ${ }^{3}$. The booms are CoilAble ${ }^{\mathrm{TM}}$ carbon fiber structures tipped with a spreader bar mechanism that rotates. When the spreader bar is rotated it changes the angle of the sails creating a pinwheel effect that will allow for roll control of the spacecraft. Pitch and yaw are controlled by ballast bars that can be moved back and forth along the booms creating center of mass center of pressure offsets.

For the SRS sail design, the edge cord curve is determined by the halyard load and the desired film stress. The compliant border width is determined by the maximum shear strain expected between the cord and sail film. For a flight sail the maximum allowable boom tip load and the minimum film stress required to tension the sail determines the curve of the edge cord and its scallop depth. Analysis has shown that very low film stresses of 0.1 to $1.0 \mathrm{psi}$ should be sufficient to maintain sail shape and adequately remove material creases for flight sails. With this low functional sail loading requirement, deployment loading requirements will likely drive boom design and halyard load requirements for an optimized system. The compliant border width requirements are driven by the thermal induced stress caused by the difference in the thermal expansion coefficients for the sail film and the edge cord material for the SRS flight sail design.

\section{Sail Design Development}

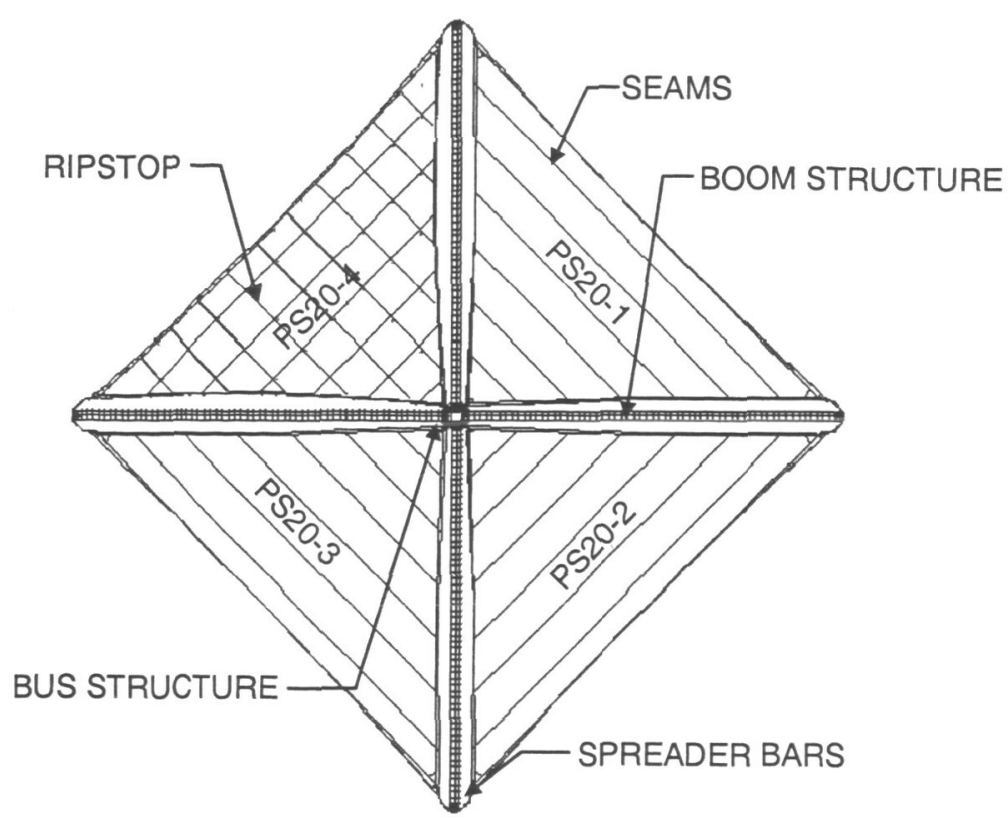

Figure 4. 20-meter ground test sail craft layout.

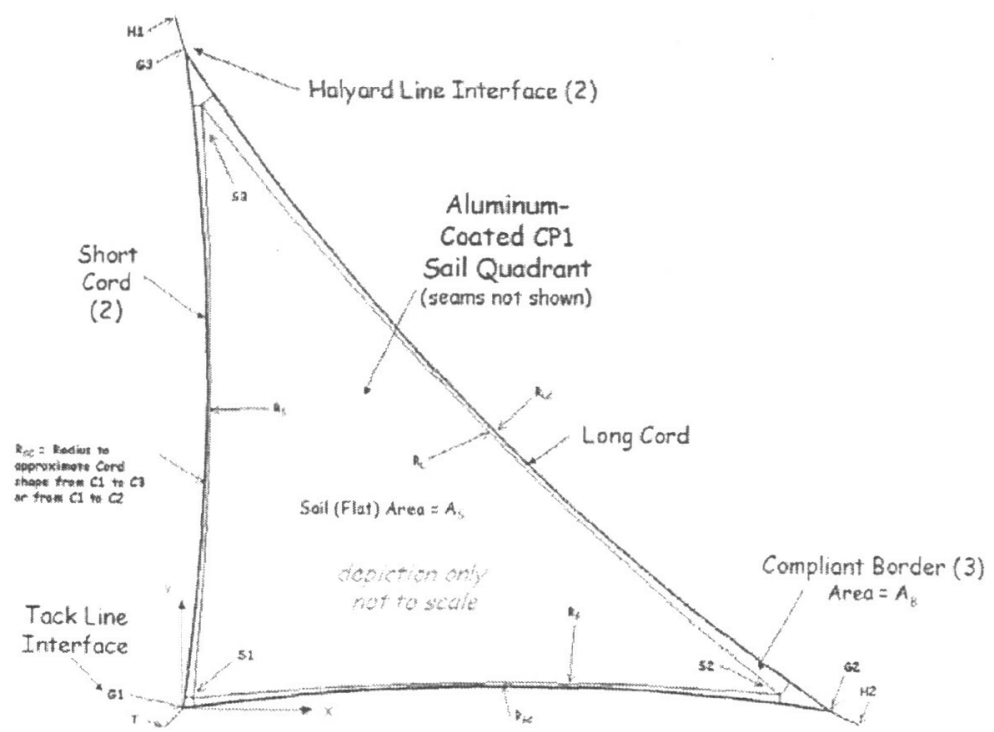

Figure 5. 20-meter ground test sail description. 
For a flight sail the billow due to solar pressure is very small and will have a minimal effect on sail shape even at very low film stresses of less than 1 psi. In a $1 \mathrm{~g}$ environment with a sail deployed in a horizontal orientation the film load caused by gravity is analogous to solar pressure, however, the gravity load weight, per unit area $\left(4.9 \times 10^{-2}\right.$ Pascal for the 20-meter sail) is four orders of magnitude greater than the solar pressure at $1 \mathrm{AU}\left(9.12 \times 10^{-6} \mathrm{Pascal}\right)$. This poses an interesting challenge for ground testing. The gravity loading has a dramatic effect on film stress during a ground deployment. In order to lift a sail off the deployment surface and suspend it the sail film stress must be increased. The film stress can be increased in two ways:

1) By increasing the cord tension (i.e. increasing the halyard loads). This increases the mechanical strain in the cord and requires a corresponding increase in compliant border width to maintain its function.

2) By increasing the scallop depth allowing for increased film stress without increasing the halyard loads.

ATK's mast design has elements that were optimized for an 80-Meter system this was then truncated to 10 and 20 -meter for ground tests. This produces a ground test system that is significantly stiffer than an optimized 10 or 20 meter boom would be. The stiffer system allows the use of higher halyard loads producing higher film stress to help lift the ground test sails off of the deployment surfaces. For the 10-meter sails the halyard tension in $1 \mathrm{~g}$ was limited by the structural capabilities of the booms, which were loaded in shear in the single quadrant demonstration. The scallop depth and the compliant border width were chosen based on a desired film stress and shear allowed by that loading. When designing the 20 -meter sail shape for the 4-sail ground test SRS optimized the sail for fill factor based on the max allowable load for an 80-meter flight system. This design was then scaled geometrically to fit the 20-meter ground test system. This design is geometrically correct in terms of the fill factor that could conservatively be achieved with a flight sail. However, a sail designed for the $1 \mathrm{~g}$ environment would need a considerably wider compliant border region to accommodate the film cord strain mismatch associated with the much higher loads required for ground testing. As a result the 20 -meter ground test sails exhibit some small amplitude wrinkling in the corners. A unique design feature called a jumper strap (See Fig. 6) connects sail corner grommets, which attach the sail to the spacecraft, to the main surface of the sail. A cone shaped patch distributes the load

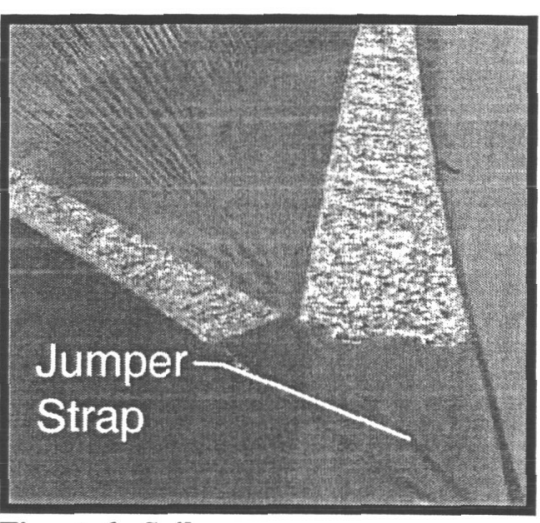

Figure 6. Sail corner. from the halyard into enough of the sail to prevent overloading the film in tension. This feature picks up load once the compliant board shear limit is exceeded. In $1 \mathrm{~g}$ there is a considerable amount of load carried by the jumper straps on the 20-meter sails, in a zero gravity environment the jumper straps would be unloaded. The jumper strap feature was developed to protect flight sail corners during ground handling, deployment, and during off nominal loading conditions such as extreme ACS maneuvers (large spreader bar movements) or extreme thermal excursions.

One of the innovative methods used to increase the fill factor for the optimized 80-meter sail design (that was scaled to produce the 20-meter sails used for ground testing) was to bias the load to the hypotenuse reducing hypotenuse scallop depth at the expense of short side scallop depth increasing the overall fill factor without changing the biaxial loading or sail mode shapes. SRS was conservative when using this technique for the existing sails and some additional fill factor gains could be made using this technique.

Further fill factor design optimization was achieved by rotating the sail short side curves in order to relocate the tack line attachment point. This was done in order to take advantage of some of the area lost to the spreader bar tips and moves the tack line attachment into the spacecraft bus structure.

\section{Sail Fabrication Process Development}

To date SRS has constructed a total of six 10-Meter solar sails, four 20-meter solar sails (all for MSFC on the ISP program) and several 3 meter test sails. All of these sails were produced as part of a sail design and production development program with the goal of improving the materials, processes and procedures with each subsequent sail construction. All with the aim of producing more and more advanced sails in order to arrive at a point where SRS had developed the technology, techniques, procedures, and materials that would allow the production of a low risk, low mass, high TRL flight sail. A number of significant technological advances in sail design concepts, material fabrication processes and assembly methods were made during this development period. These advancements are summarized below.

\section{A. Film Production and Coating}


CP1 film is a polymer film developed by NASA and produced under exclusive license by SRS Technologies ${ }^{6,7}$. $\mathrm{CP} 1$ has mechanical properties and a density similar to Duponts $\mathrm{Mylar}^{\mathrm{TM}}$ but can operate at much higher temperatures and has far superior resistance to radiation exposure. Aluminized CP1 polymer film has been flight qualified and was used for solar reflectors on several Boeing 702 commercial satellites illustrated in Fig. 6. This material (25 micron CP1) has been successfully deployed over 117 times on six separate spacecraft totaling an accumulated area of over $11,500 \mathrm{ft}^{2}\left(1,068 \mathrm{~m}^{2}\right)$ making the reflector system the largest simply supported film structure in orbit today. Prior to the start of the sail program SRS began producing 60" wide continuous CP1 film using a proprietary continuous roll film production process and had been successful in producing film in the 7 to 5 micron thickness range. One of the goals of the 10-meter development program was to produce sails as thin as 2 to 3 microns. SRS was successful at producing thinner films with the existing process and demonstrated the ability to produce film in the 2 to 7 micron thickness range.

In order for this film to be used as solar sail

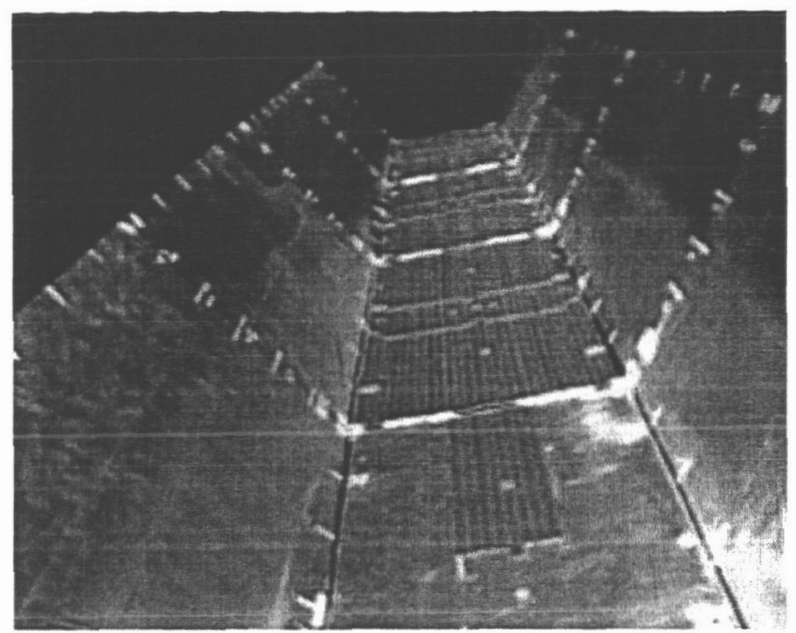

Figure 6. Boeing 702 satellite with SRS reflectors deployed. material it must be coated with aluminum to provide a reflective surface. A lack of a commercially available coating process that could reliably handle the ultra thin films being produced at SRS led to a collaborative effort between SRS and a coating vendor to develop an acceptable process for coating the solar sail films. The development of film production and coating processes that could produce large quantities of high quality aluminum coated CP1 film was a major accomplishment and is one of the enabling technologies that allows construction of ultra-thin solar sails.

\section{B. Adhesiveless Seaming, Patching and Ripstop Processes}

Conventional thin film space structures have to date been assembled using adhesives. At the start of the program, SRS had several concerns with the use of adhesives for solar sail applications. These concerns included high temperature creep, low temperature flexibility, the added mass of the adhesive, the effects of long term solar radiation on the adhesive and the potential for exposed adhesive from assembly and repair processes to cause the sails to stick together during packaging and deployment. During the 10-meter development effort a bonding method was developed to fuse or seam film sections together. This technique involves no adhesives or foreign materials and produces seams that add no mass to the sail and are as strong as or stronger than the parent material. This seaming process requires uncoated surfaces in the bond region. A method of removing the coating in the location of the seam was devised. Both the coating removal tool and the seaming tool are mounted to a $\mathrm{CNC}$ gantry and are used to seam the $\sim 60$ " wide sail film panels together to build a sail. This process allows for a lower mass, lower risk sail assembly by eliminating the need for adhesives to hold the sail panels together. SRS is continuing to improve this proprietary process and has developed a similar adhesiveless process to imbed ripstop and to patch damage from handling accidents and material defects. Pictures of some ripstop samples are shown in Fig. 7. SRS is developing a similar adhesiveless process for attaching the edge and corner features to the sail. Using this process it would then be possible to produce completely adhesiveless sails with corresponding improvements in areal density, long term space survivability and deployment risk reduction.

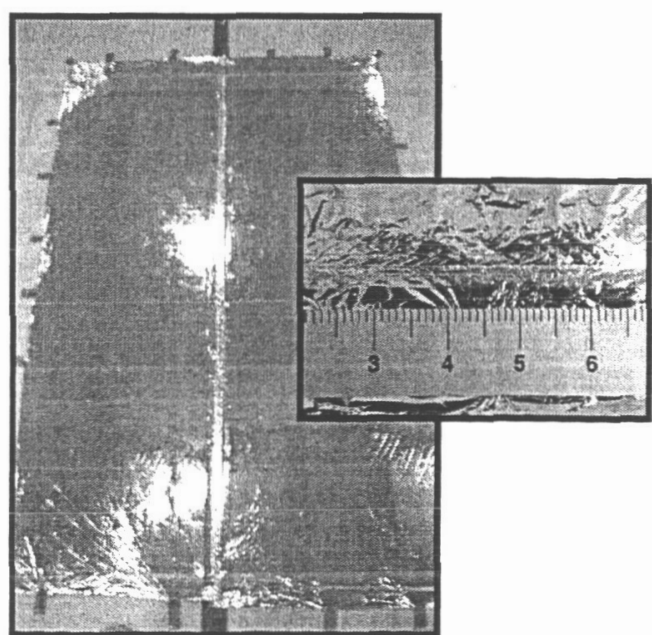

Figure 7. Sample seam and ripstop assembly. 


\section{Compliant Borders Development}

Both the 10-meter and 20-meter sails incorporate a shear compliant border that allows the main bulk of the sail and the edge cord to move independently of each other preventing wrinkling and film buckling throughout the designed operational temperature range. This feature allows the sail to provide a stable and predictable thrust throughout the operational envelope by maintaining a constant biaxial film stress on the sail material. The last two 10-meter sail test articles and all of the 20-meter sails incorporated a corner feature called a jumper strap that allows the corner loads to be redistributed to a larger area of sail material during off design cord loading such as eclipse conditions. This feature shown in Fig. 8 protects the compliant border and allows the sails to survive much larger temperature swings as well as providing addition robustness for sail deployment.

\section{Fabrication Hardware}

After the completion of the 10-meter test program a fabrication process was developed to facilitate production of the 20-meter solar sail quadrants that is readily scalable to larger sails. One objective was to improve the repeatability and accuracy of the assembly process as needed to produce balanced predictable sail performance. The 10-meter sails that SRS produced in late 2003 and early 2004 were produced on the full sized table shown in Fig. 9 using a CNC gantry system shown
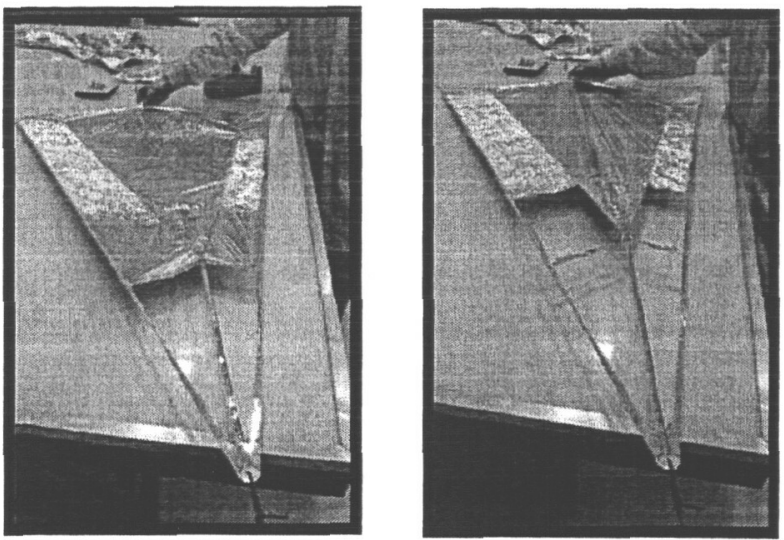

Figure 8. Jumper strap.

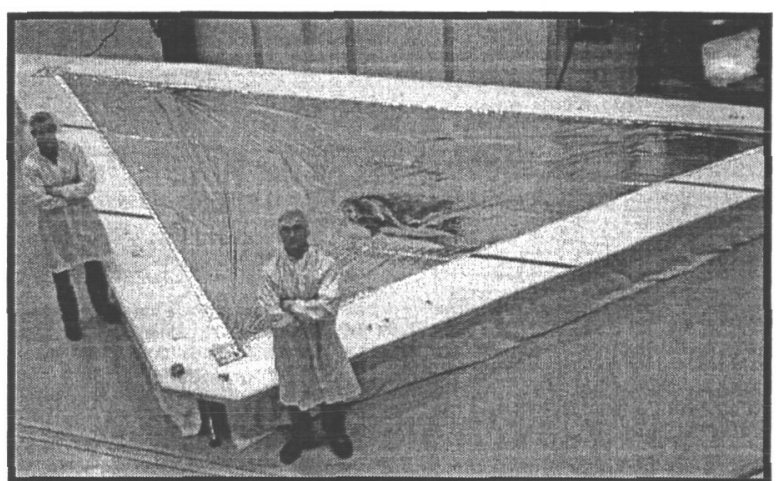

Figure 9. 10-meter sail on 10-meter assembly table.

in Fig. 10 for seaming. In order to minimize programmatic risk and to further develop the existing manufacturing technology to allow its use on sails of unlimited size it was decided that the 20-meter sails should be produced using an updated version of the existing hardware that was expanded in one direction only. A 20-meter long trapezoidal table was produced and the gantry tracks were extended for the length of the table as shown in Fig. 11. Improvements in the gantry $\mathrm{CNC}$ system and its positioning sensors along with additional sail marking and enhanced seaming hardware was developed to demonstrate the ability to accurately produce any size sail in a work space that is less than 20 feet wide and the length of the desired sail. SRS has built all of the 10-meter and 20-meter sails that have been produced to date with the film strips running parallel to the hypotenuse or long side of the triangular sail. If the sail film strips are rotated 90 degrees to run perpendicular to the hypotenuse the table length required to build a sail of a given size would be cut in half. SRS sees no significant issues with this process change and could produce sails as large as 50 meters in the existing facility using this method. Larger facilities would be required for sails over 50 meters. There are several viable options in selecting a reasonable cost facility to produce very large sails including existing hanger and industrial buildings, prefabricated steel structures and inflatable soft sided structures. 


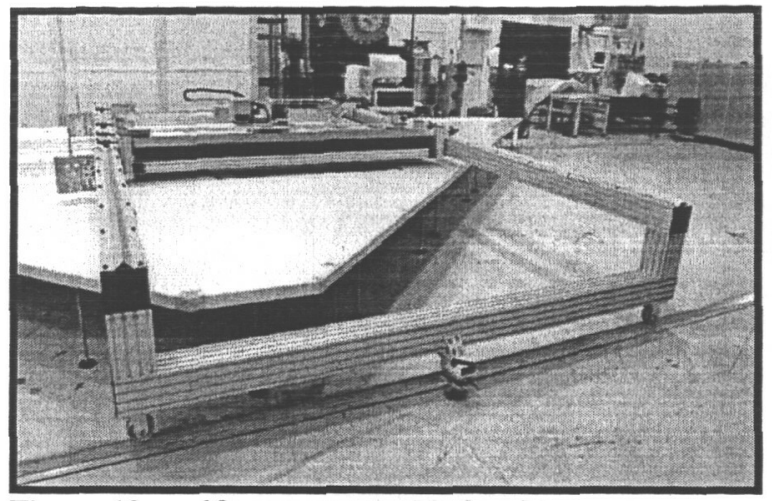

Figure 10. 10-meter assembly hardware.

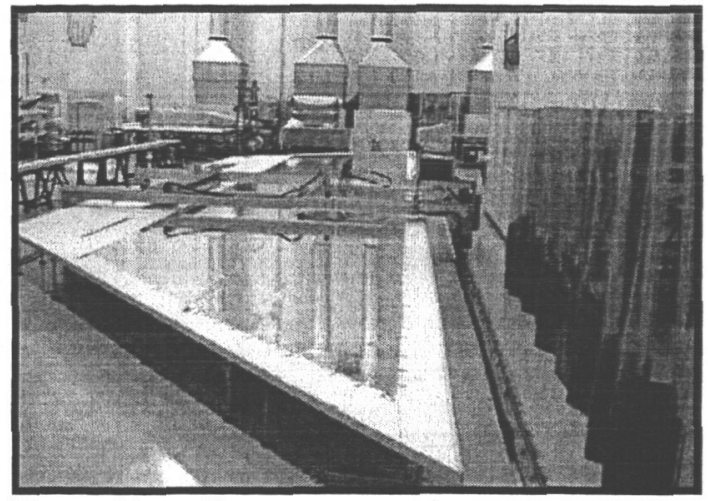

Figure 11. 20-meter assembly system.

\section{E. Packaging and Storage}

Originally, the $S^{\wedge} 4$ Team had devised a sail storage method that involved first folding the sail into 15 " strips and then accordion folding this into 5" folds for storage in the sail storage bay. The corners of each fold were to be held in place by small clips. When this was tried the gossamer nature of the sail proved to be an impediment to making these folds with the precision required to package the sail in this manner. Also the loads required to hold the sail in place were too high to allow deployments without damaging the sail membrane. After the initial attempts to fold and deploy the first 10-meter sail delivered to ATK using this method of storage it was clear that a more reliable, easer and more forgiving sail packaging system was needed. The solution that the $\mathrm{S}^{\wedge} 4$ Team arrived at was to make the $15^{\prime \prime}$ folds and then roll the sail up on a spool for deployment. This concept was first tried on the 10meter sails and has been carried on to the 20-meter sails with some minor improvements and provides a simple, reliable, and efficient sail storage and deployment system. Sails packaged in this way will easily fit in the triangular storage bay between the boom storage bays. Fig. 12 shows a 20-meter sail stored on the one of the deployment spools. A spool of this same OD and a smaller central tube diameter would be used for a 40-meter sail. Larger diameter deployment spools would be required for sails over 40-meters. As

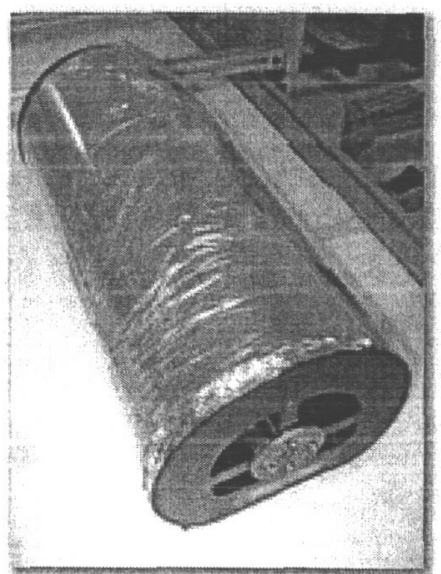

Figure 12. Stowed sail on a deployment spool. larger boom storage bays would also be required for a sail craft over 40-meters the larger sail storage spool would still fit in the available space within the proposed ATK system architecture for any size sail craft.

\section{F. Sequencer Evolution}

With the incorporation of the spool concept for sail storage and deployment the $S^{\wedge} 4$ Team determined that a method was required to provide a systematic controlled sail deployment and unfolding process as the sail came off of the spool. To accomplish this task a series of sequencers were attached to the sail. These sequencers ensure that the sail deployment is controlled, symmetric and deterministic and that the sail remains centered between the booms during deployment. For the 10-meter sails the sequencers were placed in a grid pattern thought the sail surface. The sequencers consisted of a series of cords and anchors that could be attached to moorings, these would hold the folds together until the deployment loads pulled the anchors out of the moorings and released the fold. This approach worked reasonably well on the 5 micron and 3 micron 10-meter sails. SRS and ATK began looking for improvements that could be made to reduce the mass and the risks associated with the sequencers for larger and more delicate sails. One of the sequencer design improvements made prior to the start of the first 20-meter sail build was to remove the sequencers from the main sail and place them along the cord, as illustrated in Fig. 13. This had several benefits: 
1) It eliminated attaching sequencers to the delicate sail film and allowed them to be attached to the much stronger cord improving the survivability and durability of the sequencers and the sail.

2) The number of sequencers required increases proportional to the length of the sail edges with sequencers attached along the edge, and proportional to area with sequencers distributed throughout the main sail body. On larger sails this will provide a significant weight savings.

3) Reduced the time required and risks to the sail during the installation and attachment processes.

Once sail deployments began it became obvious that additional sequencers changes would be needed to facilitate the successful deployment of the thinner sails. Further improvements were developed during initial deployment testing at SRS and are discussed below.

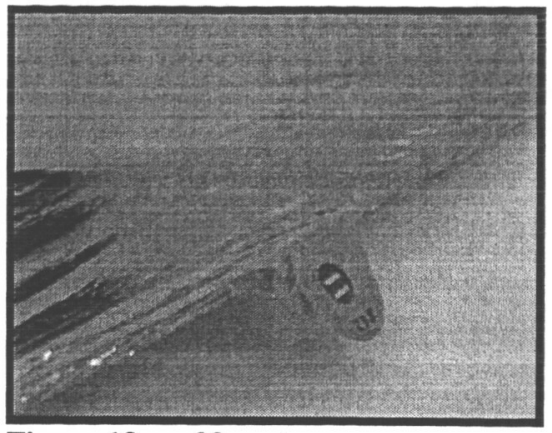

Figure 13. 20-meter sequencers located on cords.

\section{SRS In House Sail Tensioning and Deployment Testing}

Following the 10 -meter testing the $\mathrm{S}^{\wedge} 4$ team decided that SRS should conduct deployment testing prior to delivering sails to ATK for system integration and testing. This decision allowed SRS to build hardware to simulate a deployment; including two pylons that represented the ATK boom tips as well as a simulated sail storage bay. An additional benefit was that this system allowed SRS to perform deployment tests much earlier in the program than if testing had to wait until the actual 20-meter hardware was completed and checked out. Testing early provided an opportunity to correct issues that were observed and work on and check-out packaging and ground support equipment and procedures. During the initial SRS deployment tests several significant issues were identified. By identifying these issues early in the program, while the first sails were still at SRS and the subsequent sails had not been completed, time was available to solve problems in a quick and efficient manner. Two issues were discovered during these tests:

1) Adhesive from patches and the corner feature attachment process caused parts of the sail to stick to each other and sometimes caused sail damage.

2) Sequencer anchors were causing sail damage after they released as they were drug across the sail surface.

The adhesive issues were resolved by the addition of several inspection steps throughout the assembly and packaging process and the addition of some repair processes developed to eliminate "sticky spots" on the sail once they were identified. The first attempt to eliminate the sequencer issue was to try changing the thickness and the shape of the anchors. The shape change resulted in a reduction in the number of occurrences but did not eliminate the sequencer induced defect problems. In addition, the "semi-rigid" sequencer anchors posed additional risk during development as they dragged under and around the sail and sometimes initiated tears in the sail material. With the current sequencer design posing a substantial risk to sail deployment, an alternate sequencer design was sought. A concept was developed that replaced the multi use anchor and mooring design with a break away ribbon. The break away ribbons would have to be replaced after each deployment but this was considered a small inconvenience especially as a flight sail would never be redeployed in space and a few hours additional prep time between ground tests was viewed as a necessary measure for a successful deployment. The design that was first tested was attached to the old sequencer tabs with a adhesive patch on both ends and contained a single hole punched in the middle of the ribbon for a break point. Several ribbon designs were tested to produce ribbon failure loads in the desired sequencer release load range. These sequencers were attached to the PS20-1 sail prior to its first successful deployment on January 19, 2005. 
This test was repeated successfully on January 21st with PS20-1 and again on January 25th with PS20-2. A picture of the PS20-2 following its successful deployment is included as Fig. 14; PS201 and PS20-3 are visible in the background of this picture. A series of pictures illustrating the deployment sequence has been included as Fig. 15 . Since these first deployments an alternate ribbon sequencer attachment process that involves tying the ribbons to a mount and eliminates the use of adhesive in the sequencer installation process has been developed. The new attachment method was first tested on PS20-3 and then incorporated and tested on the PS20-4 sail. Following completion of PS20-4, PS20-1 was retrofitted with the tie on sequencers as well. PS20-2 was not retrofitted due to logistical and schedule concerns prior to the start of the Plum Brook test series. In addition to the tie on attachment method a redundant ribbon defect was added to each ribbon to reduce the variation in

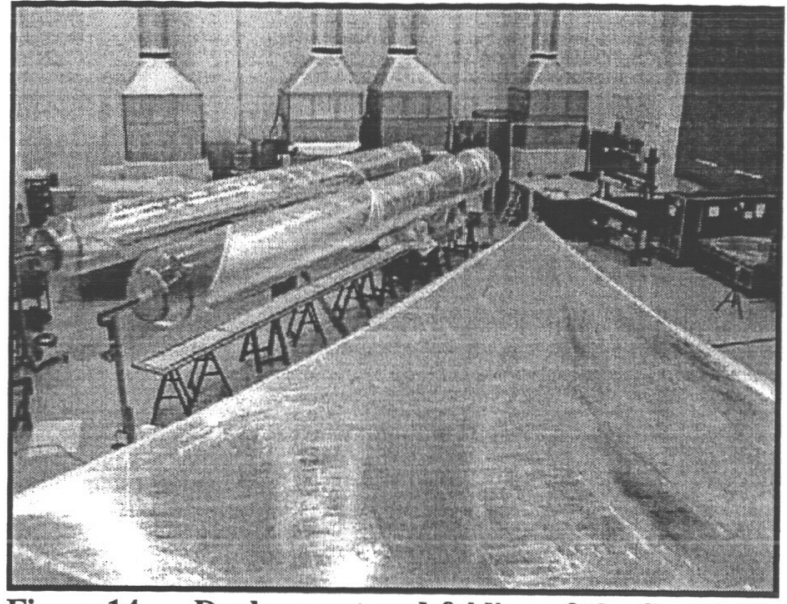

Figure 14. Deployment and folding of the first 320 meter sails. From left rear to right front sails 3, 1 and 2 are shown.

release loads. The resulting sequencer design has shown nearly an order of magnitude decrease in the release load variation during component testing and has eliminated sequencers as a source of sail damage during deployment. The separated sequencers can be seen hanging from the sail edge in Fig. 16.

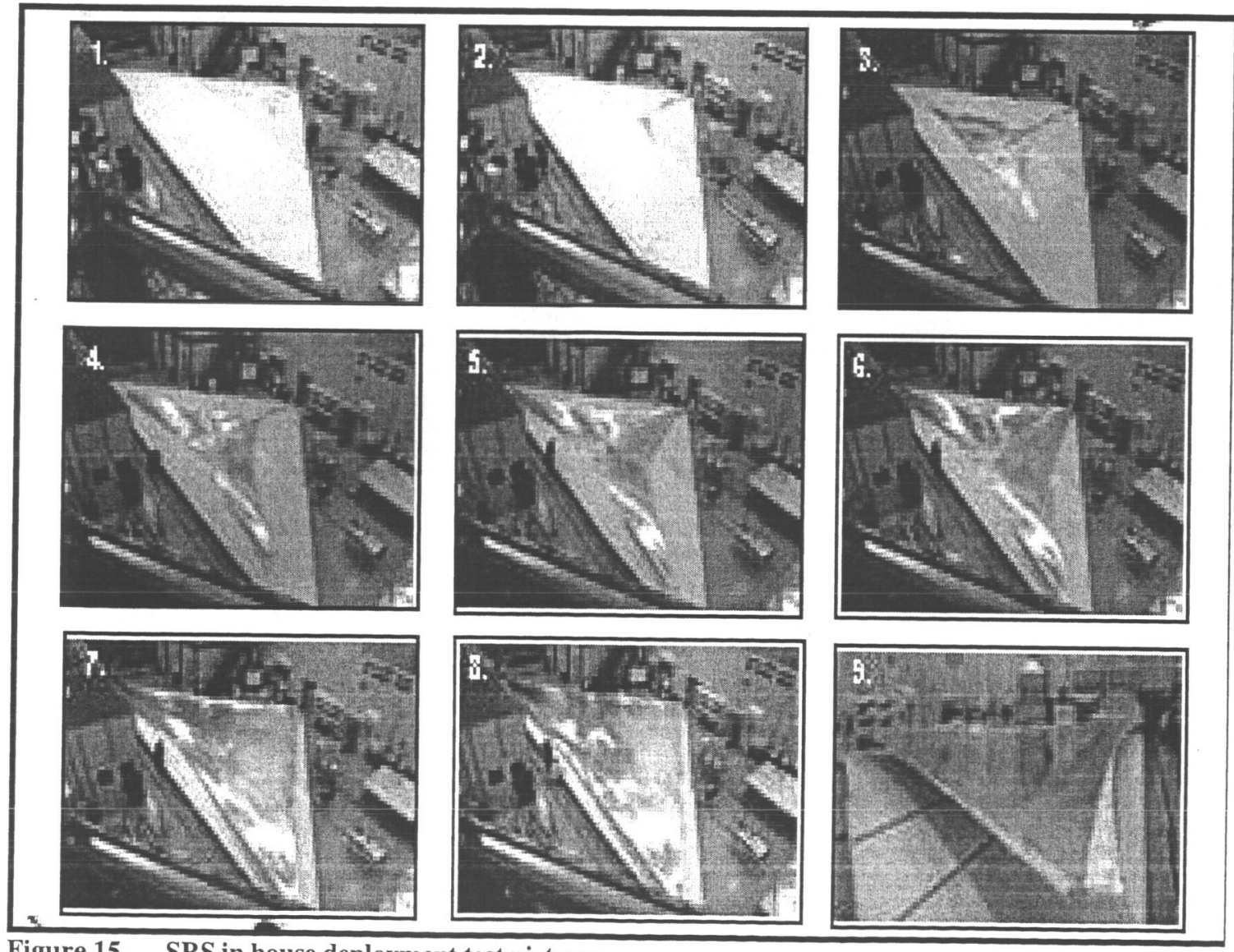

Figure 15. SRS in house deployment test pictures. 


\section{Ripstop Technology Development}

Ripstop features are desirable for the solar sail membrane structure to provide survivability and limit the impact of an undetected manufacturing or packaging defect and limit the extent to which one of these defects could propagate during deployment. Ripstop adds robustness to the system and allows a damaged sail to perform with a manageable loss in performance. The spacing of the ripstop for a flight sail should be chosen such that the worst case scenario of losing the outer most section on two adjacent sails could be overcome by the ACS system and that the associated loss of sail area would not preclude a successful mission. SRS had experimented with several concepts that could accomplish this task. A viable adhesiveless ripstop option that could be added to a sail with less than a $3 \%$ mass increase and could be accomplished in time for the fourth and final 20 meter sail build was identified in December of 2004 and demonstrated on the coupon level in January of 2005. Prior to implementation of this feature, a full up assembly test was conducted on the 3-meter assembly shown in Fig. 17. This was done to validate the planned assembly method and determine the optimal order for the assembly operations. During sample testing the adhesiveless ripstop provided around two orders of magnitude increase in the loads required to cause tear propagation in a trouser tear test. The initial ripstop testing and functional evolutions are very encouraging and this ripstop provides significant increase in sail robustness at a minimum weight penalty. This ripstop was used in the construction of PS20-4 in a 60" x 60" grid pattern, as shown in Fig. 18, and was successful at producing a sail with less than $3 \%$ mass increase due to ripstop and was shown to improve overall sail shape on PS20-4. A view of the finished PS20-4 sail and its ripstop is shown in Fig. 19.

\section{Sail Mass Assessment}

A sail mass asesment has been made on each of the sails produced to date by SRS. A bar graph showing the mass breakdown for the four PS20 solar sails is shown in Fig. 20. This data including a top level componant mass breakdown and predictions for flight sized sails produced using the same materials and assembly methods as those used to produce the PS20-4 sail is shown in the table listed as Fig 21. As shown in both Fig 20 and 21 the sail film mass is the driving factor in total sail mass. Additional film production research will lead to further reductions in film thickness to less than 1 micron enabling production of sails with areal densities as low as $2.0 \mathrm{~g} / \mathrm{m}^{2}$ using the current design, resulting in a system areal density of as low as $5.3 \mathrm{~g} / \mathrm{m}^{2}$ (sail and structure). These areal densities are low enough to allow nearly all of the Solar Sail missions that have been proposed by the scientific community. The fundamental technology and processes required to produce these sails has been

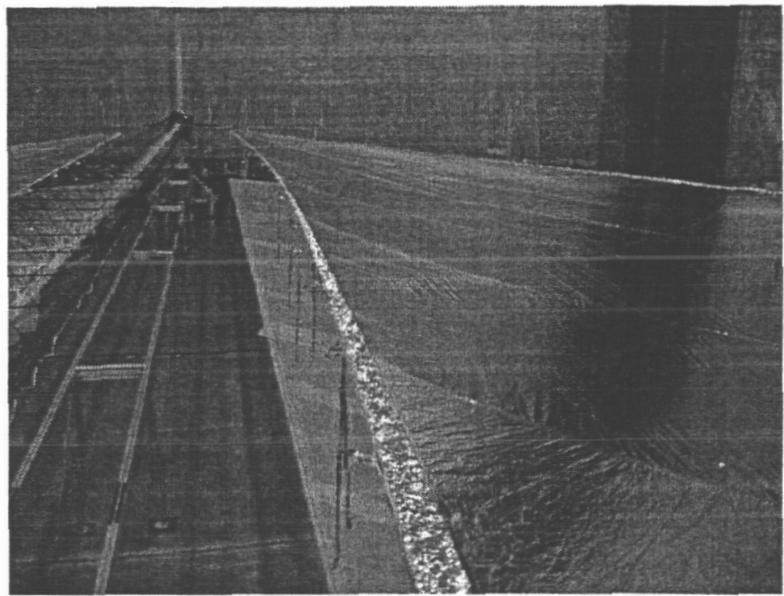

Figure 16. Separated sequencers hanging from solar sail.

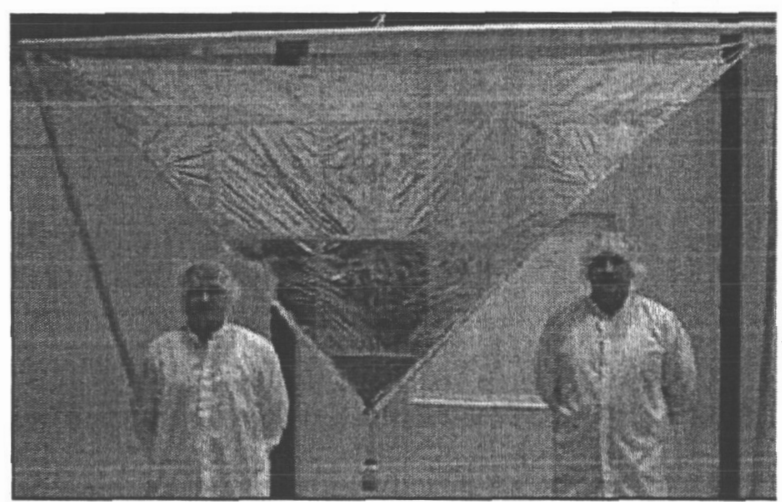

Figure 17. 3-Meter ripstop demonstration sail.

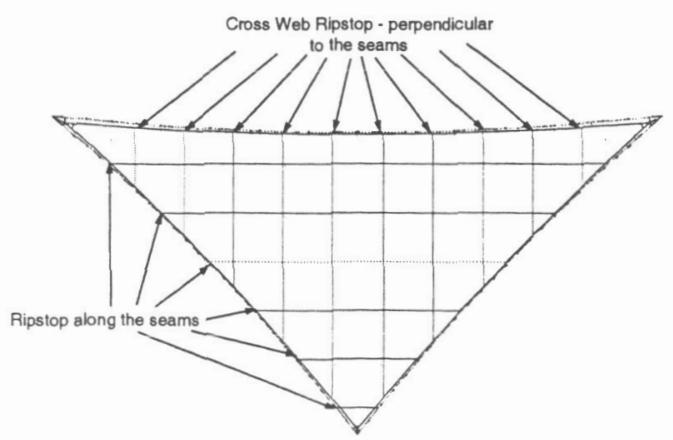

Figure 18.

10 
demonstrated on the 20 -meter $\mathrm{S}^{4}$ sails that have recently completed ground tests. As a result of the 20-meter development effort SRS currently has the equipment, processes and expertise in place to allow for the production of 40 to 50 meter flight sails in the existing SRS facility using nearly all of the same materials processes and support hardware that was used to produce the PS20 sails.

\section{20-meter $S^{4}$ System Testing at NASA Plum Brook}

SRS provided on sight technical support and supported sail folding packaging and repair operations during the month long test series at NASA Glenn's Space Power Facility at Plum Brook Station, shown in Fig. 22. The $S^{4}$ Plum

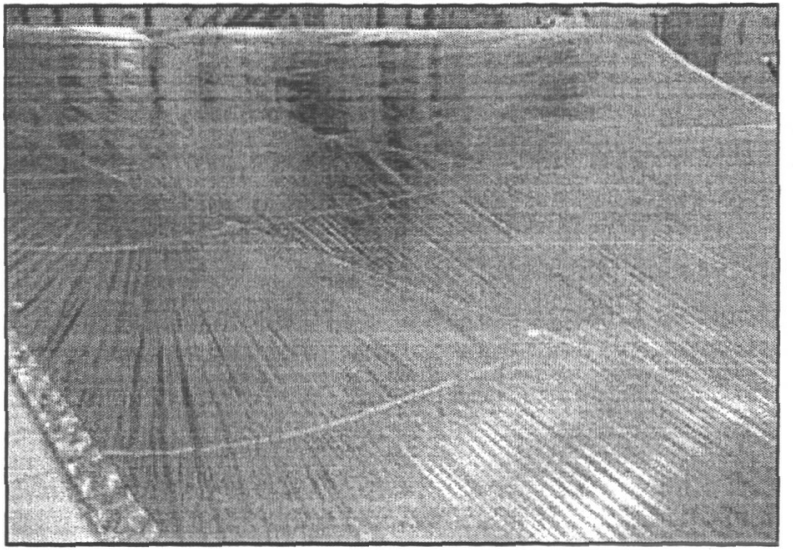

Figure 19. Brook test series was extremely successful resulting in 3 deployments with only a few correctable issues. As with most all test programs there were some unanticipated and challenging developments during the course of testing. The $S^{4}$ team worked through these challenges and collected a significant amount of data and gained invaluable hardware experience and knowledge in the process. The following is a summary of the significant test events listed in chronological order. Data analysis and reduction is still ongoing and an additional series of tests including vibration testing of the assembled sail craft, ascent venting and post ascent venting ambient deployment tests are scheduled to occur prior to completion of the current NASA ISP $\mathrm{S}^{4}$ contract.

\section{A. Ambient Pressure Deployment Test}

Following facility and system set up at NASA Glenn's Space Power Facility at Plum Brook Station, the first full system deployment test of a $\mathrm{S}^{4}$ system was conducted on Friday April 22, 2005. The boom and sail deployments went as planed and are shown in Figs 23,24 , and 25 with only minor damage to the sails resulting in the loss of $\sim 0.013 \%$ of the effective area on the PS20-1 sail.

\section{B. Primary ACS Functional Testing}

Following the successful ambient deployment, tests were conducted of the spreader bar rotational function that is intended to act as the primary ACS roll control mechanism. These tests were conducted with greater than expected sail loads variation due to variations in halyard length, negator loading, sail mass, sail sag and sail shape all of these contributing factors led to off nominal sail loading that likely resulted in higher than anticipated cord loading in the sails. In addition to the higher than expected loading during 0 deg loading analysis preformed by ATK shows that during spreader bar rotations the load balance between the sail edge cords would shift so that as the spreader bar rotated out of plane more and more of the halyard load would be transferred to the hypotenuse cord of the sail. This analysis was not made available to SRS until after the spreader bar testing. A materials control oversight had resulted in the PS20-1 and PS20-2 sails being produced using a different cord material (6K AS4) than what had been called for in the sail design (6K IM9). The errant material was evaluated and where it had reduced structural margin when compared to the design material it was determined that it still had a factor of safety of more than 2 at the halyard design loads and the decision was made to leave

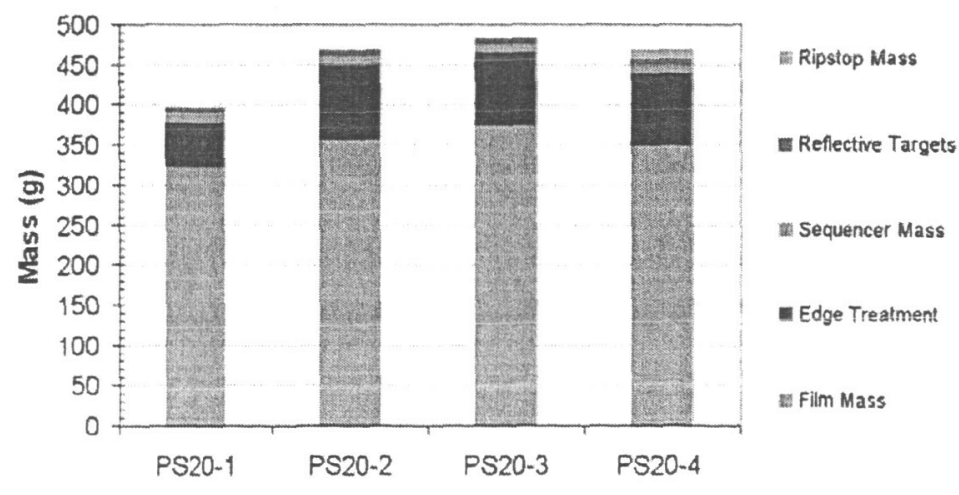

Fig. 20 PS20 mass graph. 
$S^{\wedge} 4$ SINGLE QUADRANT MASS HISTORY AND PREDICTIONS

\begin{tabular}{|c|c|c|c|c|c|c|c|c|c|c|c|c|c|}
\hline & \multirow{2}{*}{\multicolumn{6}{|c|}{ 10-Meter Class Sails }} & \multirow{2}{*}{\multicolumn{4}{|c|}{ 20-Meter Class Sails }} & \multirow{2}{*}{\multicolumn{3}{|c|}{ Flight Sized Sails* }} \\
\hline & & & & & & & & & & & & & \\
\hline & $\begin{array}{c}\text { 1st LaRC } \\
\text { Sail }\end{array}$ & \begin{tabular}{|c|}
$\begin{array}{c}\text { Workhorse } \\
\text { Sail }\end{array}$ \\
\end{tabular} & RS5 Sail & RS3 Sail & LRS5-1 & LRS5-2 & PS20-1 & PS20-2 & PS20-3 & PS20-4* & 40 Meter $*$ & 80 Meter $*$ & 120 Meter * \\
\hline $\begin{array}{c}\text { Area of the Flat or Effective } \\
\text { Region }\left(m^{\wedge} 2\right)\end{array}$ & 17.814 & 14.03 & 14.03 & 14.03 & 14.03 & 16.312 & 75.61 & 75.61 & 75.61 & 75.61 & 302.44 & 1209.76 & 2724.84 \\
\hline $\begin{array}{l}\text { Grommet to Grommet } \\
\text { Hypotenuse Length (m) }\end{array}$ & 9.9 & 8.9 & 8.9 & 8.9 & 8.9 & 8.9 & 18.8 & 18.8 & 18.8 & 18.8 & 37.6 & 75.2 & 112.8 \\
\hline $\begin{array}{l}\text { Average Film Thickness } \\
\text { (mierons) }\end{array}$ & 7.4 & 5.14 & 4.98 & 2.94 & -5 & $\sim 5$ & 2.77 & 3.08 & 3.23 & 3.54 & 3 & 3 & 3 \\
\hline Film Mass (grams) & 240 & 111 & 108 & 64 & 108 & 123 & 322 & 357 & 374 & 409 & 1396 & 5584 & 12564 \\
\hline Edge Treatment Mass (grams) & 67 & 28 & $\sim 20$ & $\sim 20$ & -20 & $\sim 23$ & 57 & 92 & 80 & 50 & 100 & 200 & 300 \\
\hline Sequencer Mass (grams) & 0 & 0 & 0 & 3 & 0 & 0 & 11 & 11 & 12 & 12 & 24 & 48 & 84 \\
\hline Total Mass (grams) & 307 & 138 & 122 & 88 & 120 & 142 & 397 & 467 & 472 & 485 & 1564 & 5984 & 13272 \\
\hline $\begin{array}{l}\text { Sail Areal Density } \\
\text { (grams/meter^2) }\end{array}$ & 17.23 & 9.84 & 8.70 & 6.27 & 8.55 & -8.6 & 5.25 & 6.18 & 6.24 & 6.41 & 5.17 & 4.95 & 4.87 \\
\hline
\end{tabular}

"Predicted based on geometric scaling of PS20-4, a 60" $\times$ 60" Ripstop Grid and a 3 micron film thickness

"* Includes 60" X 60" Ripstop grid

Fig 21. S4sail mass history and prediction table

the PS20-1 and PS20-2 sails as they were produced. In addition to having a lower UTS the 6K AS4 fiber has more than twice the linear density of a $6 \mathrm{~K}$ IM9 cable. There was insufficient lead time to procure $6 \mathrm{~K}$ IM9 material and maintain the build schedule, however 12K IM9 was in stock at SRS and had more than twice the UTS of the 6K AS4 material as well as a slightly lower mass per unit length. A decision was made to use the $12 \mathrm{~K}$ IM9 on hand for the PS20-3 and PS20-4 assemblies. The combination of significantly higher loading and lower than originally intended structural margin in the edge cords on PS20-1 and PS20-2 resulted in failure of the edge cord on the PS202 sail during $45 \mathrm{deg}$ excursions of the spreader bar tips. The resulting sail damage was field repaired and testing was resumed.

\section{Vibration Testing}

Vibration testing was performed by LaRC in both atmospheric and vacuum conditions and data is currently being analyzed. An unexpected phenomenon occurred during pump down to vacuum of the deployed system in that the sag of the sails increased by several inches. The phenomenon was observed to reverse its self during chamber venting and then reoccurred during subsequent pump dawn. The root cause analysis of the issue indicates that the primary cause of the phenomenon is likely the combination of the air currents and condensation loading on the sails during pump dawn and chamber venting and the hysteresis in the sail support mechanism. Very small (less than 1/8") halyard movements would account for the changes in sail sag observed in the test and could easily result form the known halyard hysteresis and measured load variations during chamber pump down and venting. This is a ground test phenomenon only as the forces acting on the sail at $1 \mathrm{~g}$ during pump down are $~ 5000$ times greater than the solar loading that would occur during a flight and any sail tension variations due to cyclic solar pressure loading would be negligible with respect to halyard loading.

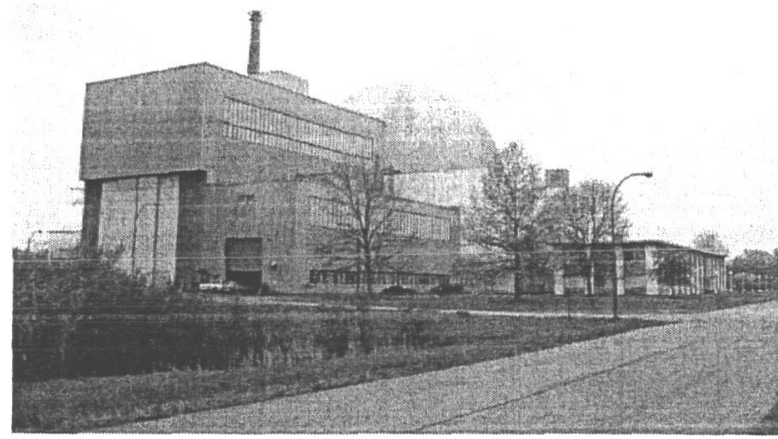

Fig. 22.

12

American Institute of Aeronautics and Astronautics 


\section{Sail Retrofit Repair and Packaging}

Once sail vibration testing was complete the sails were removed from the chamber and PS20-3 and PS20-4 were folded and packaged using the SRS developed sail folding tubes and folding tables. Once they were folded new tie on sequencers were installed and the sail was rolled onto the deployment spools using the sail rolling fixture. PS20-1 and PS20-2 were retrofitted with the addition of an 12K IM9 cord on the hypotenuse of each sail to protect against the possibility of additional cord overload failures during the remaining test series. Following the repairs PS20-1 and PS20-2 were folded sequenced and rolled onto the deployment spools. Sail folding is shown in Fig. 26 and 27. All of this activity was completed in 2 days with a tremendous effort by both the SRS and ATK test support personnel.

\section{E. Vacuum Deployment Test}

Following sail retrofit and packaging, the sails were reinstalled into the spacecraft, the booms were restowed, and the system was prepared for the first vacuum deployment. The chamber was pumped down to $\sim 2 \times 10^{-5}$ torr and the vacuum deployment was initiated the evening of Friday May 13, 2002. The deployment sequence was paused to evaluate two minor anomalies during boom deployment. The first anomaly was the fact that visual inspection via closed circuit video monitoring of the test was unable to confirm that the boom tips had released. When the next step in the deployment process was begun it was evident that the mechanisms had indeed released and everything was nominal. The second anomaly was a separation of one of the halyards from the boom during deployment. This caused no further issues and had no impact on the rest of the test. Sail deployment, as illustrated in Fig 31, was flawless and symmetrical exhibiting no stiction, or static issues. Post test sail inspections revealed no significant sail damage on any of the four sails with only 6 total defects all of less than 2" in length noted on sails PS20-1 PS20-2 and PS20-3 combined, none of which produced any reduction in effective sail area. There were no visible defects on PS20-4.

\section{F. Sail Packaging}

All 4 sails were repackaged and the sail craft was readied for thermal vacuum deployment testing in less than 3 working days.

\section{G. Cold Soak Deployment Test}

The vacuum deployment with thermal gradient test was initiated on Thursday May 19. The gradient achieved for the test was $23.4 \mathrm{C}$ and was short of the goal of $40 \mathrm{C}$ for the test. Radiative and conductive links to the chamber

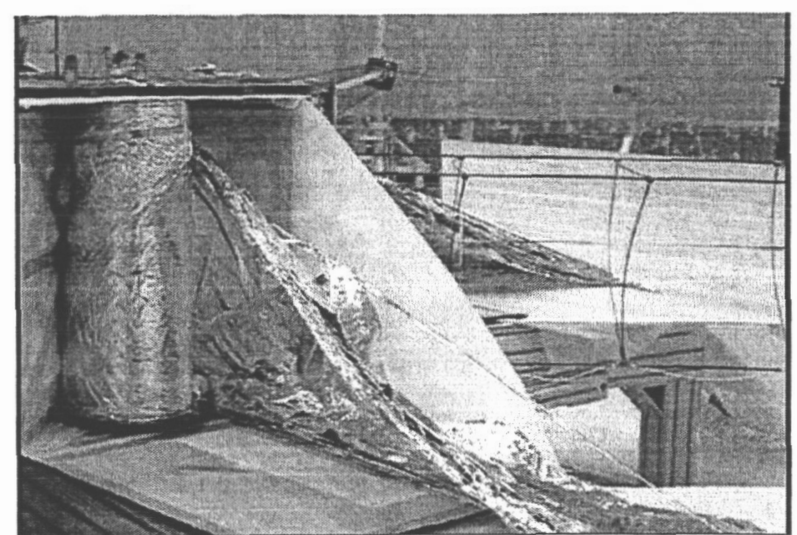

Fig. 23.

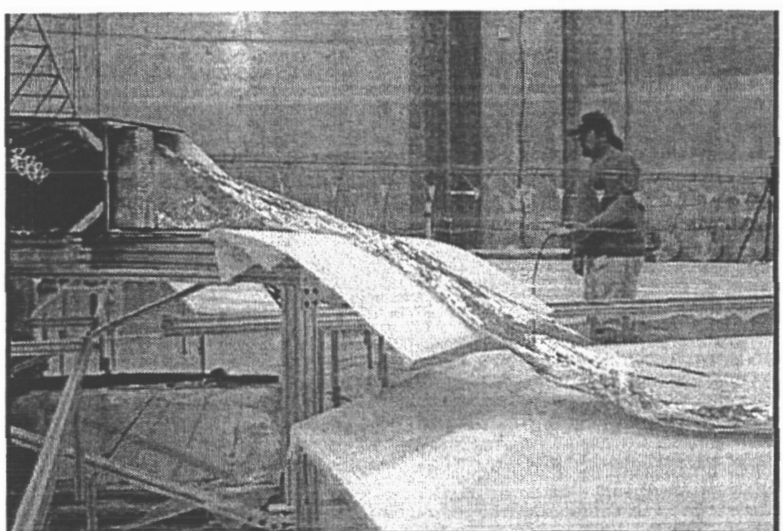

Fig. 24.

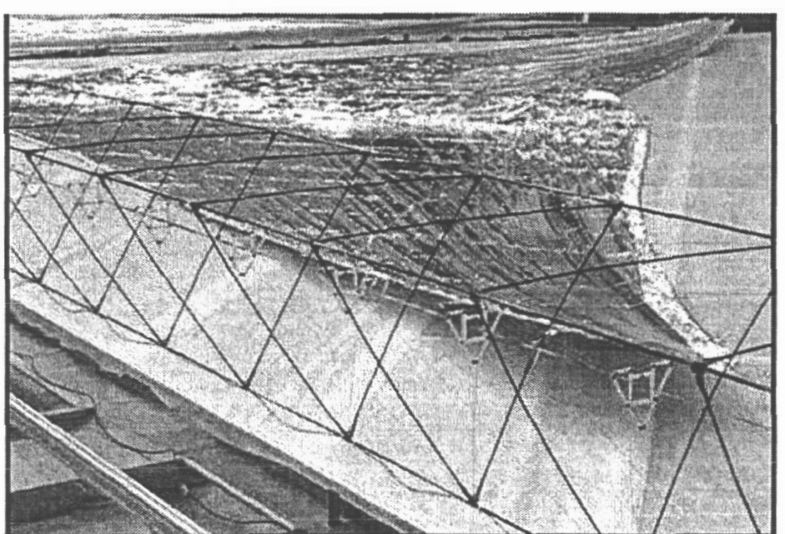

Fig. 25. 
limited the achievable gradient for this test. As there was no way to achieve the desired $40 \mathrm{C}$ gradient the deployment was conducted at the $23.4 \mathrm{C}$ gradient that was achieved. Boom deployment proceeded as planned with no anomalies. Sail deployment began normally but was halted and the test was aborted mid way through sail deployment when it became evident that an installation error had been made on one of the 4 sails with the halyards attached to the wrong sail corners. This error could have been avoided by additional checks, attention to detail and could be made nearly impossible with simple hardware change. The chamber was vented and the test personnel entered the chamber, corrected the issue and completed the deployment at atmospheric pressure. Post deployment inspections revealed one small sail defect resulting in the loss of $0.043 \%$ of the effective sail area on PS20-3 this damage was repaired prior to further testing.

\section{H. Repeated Primary ACS Functional Testing}

Following the Cold Soak deployment test, ATK repeated the spreader bar movement tests using the retrofitted and deployed sails. These tests were successful no sail damage or issues resulted from the activities.

\section{Sail Packing}

After all of the Plum Brook testing was complete the sails were restored in preparation for shipment and additional testing to be preformed at other facilities.

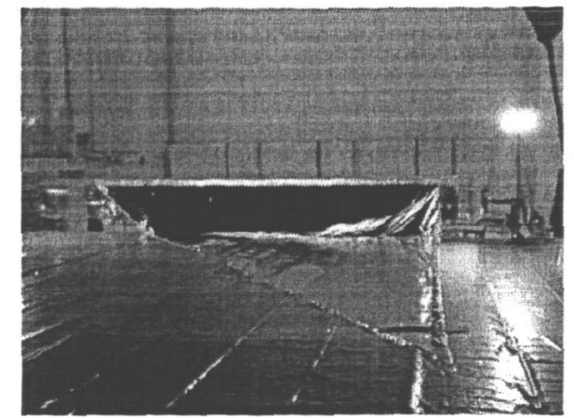

Fig. 26.

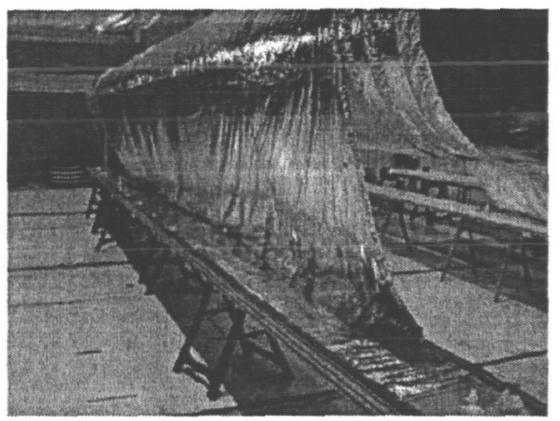

Fig 27.

\section{J. Additional Testing Plans}

ATK and SRS plan to conduct additional testing over the next few months including vibration testing of the assembled sail craft, ascent venting and post ascent venting ambient deployment tests. These tests will occur at several different facilities in the coming months and will verify that the design is capable of withstanding the rigors of launch.

\section{Test Result Discussion and Lessons Learned}

Overall the Plum Brook Testing was extremely successful resulting in 3 deployments with only a few correctable issues. Reoccurrence of all of the issues observed during this test series that could affect a flight mission could be prevented with the inclusion of flight level QA and inspection systems and procedures, some minor hardware changes or additional system monitoring and feed back loops. Flight level QA and inspection was not included on this program as it was a technology development program with very aggressive technical and schedule goals and insufficient funding and schedule to develop and implement the rigorous procedural and inspection criteria that a flight program would require. The sail film defects that occurred during the ambient pressure and cold vacuum deployments were the result of exposed adhesive related to previous sail repairs. The sails used during these tests had experienced from 1 to 9 test deployments at both SRS and ATK prior to the start of Plum Brook testing. The ground sail handling and packaging processes are relatively hard on the sails when compared to deployment and have resulted in numerous sail defects and repairs. The pressure to meet the very aggressive test schedule and the lack of a ridged inspection process likely contributed to the defective repairs being overlooked during sail packaging and inspection activities. A more rigorous repair and inspection process as well as the adaptation of the SRS adhesiveless sail repair technique and equipment for use in field repairs could be used to greatly reduce or eliminate these types of occurrences on a flight program. The improperly installed halyards observed during the thermal vacuum test was the result of inattention to detail and the fact that the system stowage procedure did not require an inspection of the halyard sail attachment by a second person to verify that the attachment was made correctly. The inclusion of this inspection and color coded tags or other easily recognizable labeling devices on both the sail corners and halyard clips could be used to prevent reoccurrence in a flight program. A material acceptance and control procedure for flight hardware would prevent the unidentified material substitution seen on the cord material 
for PS20-1 and PS20-2. The inclusion of a simple commercially available flight proven release indicator switch would provide positive verification of boom release that was in question at the start of the ambient temperature vacuum deployment test.

\section{Conclusion}

Over the past two years, with funding from NASA's ISP program, SRS has developed the design and production technologies required for the production of large, high TRL solar sails. The development activities and testing required to conduct the 10-meter and 20-meter deployment tests has greatly improved the design and fabrication knowledge base to the point where the design and construction of large flight-like sails with high confidence is possible. Additional materials testing and analysis would be beneficial prior to building a flight system. The remaining technical concerns with a flight test system could be answered early on as part of the design and development effort. This activity would benefit from the use of the existing hardware as a development tool for the flight system. The S4 solar sail team has identified the tasks that would be needed and is poised to begin work on the design and development of a flight system. The enormous potential and mission enabling capabilities of a solar sail propulsion system and the maturity of the technology that has resulted from the NASA ISP investment in this technology make it a prime candidate for near term flight demonstration and use. Solar Sail propulsion systems would be capable of maintaining non-Keplerian, high inclination and retrograde orbits as well as artificial LaGrange points for long duration missions. The availability of a propulsion system that is low mass and low cost and can maintain these orbits indefinitely enables a wide array of observational and communications missions. With the tremendous capabilities of solar sails and the relatively mature state of the technology the next logical step is a flight validation mission.

\section{Acknowledgments}

The work described in this paper was funded in whole or in part by the In-Space Propulsion Technology Program, which is managed by NASA's Science Mission Directorate in Washington, D.C., and implemented by the In-Space Propulsion Technology Office at Marshall Space Flight Center in Huntsville, Ala. The program objective is to develop in-space propulsion technologies that can enable or benefit near and mid-term NASA space science missions by significantly reducing cost, mass or travel times.

\section{References}

${ }^{1}$ Montgomery, E., and Johnson, L., "The Development of Solar Sail Propulsion for NASA Science Missions to the Inner Solar System", AIAA Structures, Structural Dynamics, \& Materials Conference, $5^{\text {th }}$ Gossamer Spacecraft Forum, Palm Springs, CA, April 19-22, 2004.

2"The Sun-Earth Connection Roadmap 2003-2028, Understanding the Sun, Helisphere, and Planetary Environments as a Single Connection System," NP-202-8-500-GSFC. Available at http://sec.gsfc.nasa.gov

${ }^{3}$ Murphy, D., McEachen, M., Macy, B., and Gaspar, J., Demonstration of a 20-m Solar Sail System, AIAA 2005-2126, $46^{\text {th }}$ AIAA Structures, Structural Dynamics, \& Materials Conference, $6^{\text {th }}$ Gossamer Spacecraft Forum, Austin, TX, April 18-21, 2005.
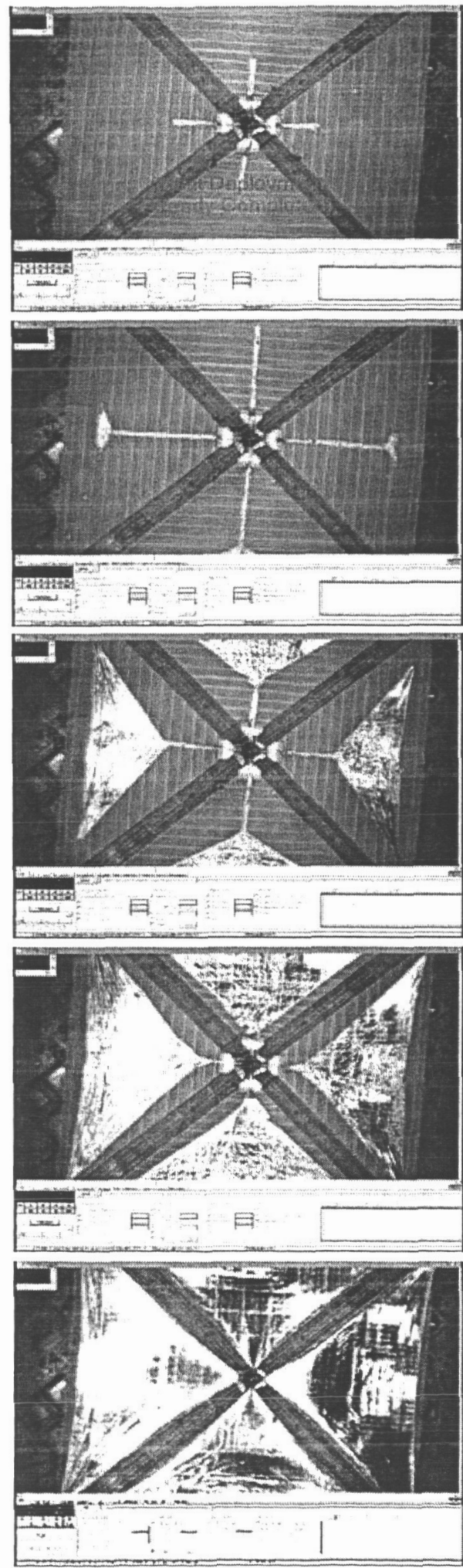

Fig 28. 
${ }^{4}$ Laue, G., et al, Innovative Structural Design Features for a $10 \mathrm{~m}$ Solar Sail Demonstration, AIAA 2004-1508, 45 ${ }^{\text {th }}$ AIAA Structures, Structural Dynamics, \& Materials Conference, $5^{\text {th }}$ Gossamer Spacecraft Forum, Palm Springs, CA, April 19-22, 2004.

${ }^{5}$ Moore, J., et al, High Fidelity Element Based Modeling for Solar Sail Thrust Vector Prediction from Flexible Sail Models, $52^{\text {nd }}$ Joint Army-Navy-NASA-Air Force (JANNAF) Propulsion Meeting, Las Vegas, Nevada, May 10-13, 2004.

${ }^{6}$ Murphy, D., Trautt, T., McEachen, M., Messner, D., Laue, G., and Gierow, P., "Progress and Plans for System Demonstration of a Scalable Square Solar Sail," AAS 04-105, 14 th AAS/ALAA Space Flight Mechanics Meeting, 2004.

${ }^{7}$ Murphy, D. M., Murphey, T. W., and Gierow, P. A., "Scalable Solar-Sail Subsystem Design Concept," AIAA Journal of Spacecraft and Rockets, Volume 40, No. 4. pp. 539-547, July-August 2003.

Laue, G., Moore, J., Case, D., Fabrication and Deployment Testing of 20-Meter Solar Sail Quadrants for a Scaleable Square Solar Sail Ground Test System, Gossamer $46^{\text {th }}$ AIAA/ASME/ASCE/AHS/ASC Structures. Structural Dynamics \& Materials Conference 